DOI: http://dx.doi.org/10.18764/2358-4319.v12n1p11-32

\title{
Atuação de educadores em prol de uma escola pública, laica e gratuita na cidade do Rio de Janeiro
}

Vania Finholdt Angelo Leite ${ }^{1}$

\section{RESUMO}

Este ensaio pretende refletir sobre o desmonte da educação pública, laica e gratuita que vem ocorrendo no Brasil desde 1990. Defendo a ideia de que há intenção dos governantes no desmonte da educação no Brasil, mas, em contrapartida, os educadores/atores na escola traduzem/interpretam as políticas de acordo com os valores e projetos pedagógicos de cada escola. Construo esse argumento, a partir do conceito de atuação das políticas (BALL et al., 2016) e dos exemplos de pesquisas desenvolvidas de 2009 a 2016, durante a proposta educativa da Rede Municipal da Cidade do Rio de Janeiro, na gestão de Eduardo Paes na prefeitura da cidade. Nesse ensaio, os exemplos mostraram um peso significativo dos valores defendidos pelos educadores na interpretação/tradução da política. Os educadores cumpriram em parte a proposta, adequando-a a seus propósitos, isto é, que seus alunos aprendessem e se envolvessem com a leitura prazerosa. Eles não foram corrompidos pela lógica do novo gerencialismo e performatividade e nem mercantilizaram seu trabalho educativo.

Palavras-chave: Política Educativa. Atuação das políticas. Educação pública.

\section{Enacting of educators in favor of a public, secular and free school in the city of Rio de Janeiro}

\section{ABSTRACT}

This essay intends to reflect on the dismantling of public, secular and free education that has been taking place in Brazil since 1990. I defend the idea that there is the intention of the government in the dismantle

1 Doutora em Educação, Pontifícia Universidade Católica do Rio de Janeiro. Professora Adjunta da Universidade do Estado do Rio de Janeiro (UERJ) e do quadro permanente do Programa de Pós-Graduação em Educação Processos formativos e desigualdades sociais. E-mail: vfaleite@uol.com.br 
education in Brazil, but, on the other hand, that the educators / actors in the school translate / interpret the policies according to the values and pedagogical projects of each school. I construct this argument based on the concept of policy enactments (BALL et al., 2016) and the research examples developed from 2009 to 2016 during the educational proposal of the Municipal Network of the City of Rio de Janeiro in the management of Eduardo Paes in the city hall of the city. In this essay, the examples showed a significant weight of values advocated by educators in the interpretation / translation of politics. The educators partially fulfilled the proposal by adapting it to their purposes, that is, that their pupils learn and become involved in reading pleasure. They were not corrupted by the logic of new managerialism and performativity, nor did they market their educational work.

Keywords: Educational Policy. Policy enactments. Public education.

\section{Actuación de educadores en pro de una escuela pública, laica y gratuita en la ciudad de Río de Janeiro}

\section{RESUMEN}

Este ensayo pretende reflexionar sobre el desmonte de la educación pública, laica y gratuita que sigue ocurriendo en Brasil desde 1990. Defiendo la idea de que hay intención de los gobernantes en el desmonte de la educación en Brasil, pero, en contrapartida, los educadores/ actores en la escuela traducen/interpretan las políticas de acuerdo con los valores y proyectos pedagógicos de cada escuela. Construyo ese argumento, a partir del concepto de actuación de las políticas (BALL et al., 2016) y de los ejemplos de investigaciones desarrolladas de 2009 al 2016, durante la propuesta educativa de la Red Municipal de la ciudad de Río Janeiro, en la gestión de Eduardo Paes. En este ensayo, los ejemplos mostraron un peso significativo de los valores defendidos por los educadores en la interpretación/traducción de la política. Los educadores cumplieron en parte la propuesta, adecuándola a sus propósitos, es decir, que sus alumnos aprendieran y se involucraran con la lectura placentera. Ellos no fueron corrompidos por la lógica del nuevo gerencialismo y perfomatividad ni mercantilizaron su trabajo educativo.

Palabras clave: Política Educativa. Actuación de las políticas. Educación pública. 


\section{Introdução}

Este ensaio pretende refletir sobre o desmonte da educação pública, laica e gratuita que vem ocorrendo no Brasil desde 1990.

Defendo a ideia de que há intenção dos governantes no desmonte da educação no Brasil, mas, em contrapartida, os educadores/ atores na escola traduzem/interpretam as políticas de acordo com os valores e projetos pedagógicos de cada escola.

Construo esse argumento, a partir de exemplos ocorridos na reforma educativa da Rede Municipal da Cidade do Rio de Janeiro, no período de 2009 a 2016, na gestão de Eduardo Paes na prefeitura da cidade.

O caso da reforma educativa dessa cidade não é isolado, está relacionado com mudanças globais, ao redor do mundo, e também, outros governos vêm adotando soluções semelhantes para os problemas educacionais. Essa política global para educação, geralmente centrada na performatividade, no novo gerencialismo, assume diferentes formas e graus em cada sociedade/contexto.

Performatividade (BALL, 2004; 2006) é um mecanismo de controle indireto ou a distância que substitui a intervenção e a prescrição pelo estabelecimento de objetivos, pela prestação de contas e comparação.

O controle a distância das escolas ocorre por meio da descentralização, que passa a lhes dar autonomia financeira, administrativa e pedagógica. No entanto, o controle do Estado se mantém por meio da produtividade e/ou resultados alcançados pelas escolas, instituídos pelo novo gerencialismo, assinalado por Gewirtz e Ball (2011, p.154), que apresentam as seguintes características: "a) Sistema de valores orientado ao cliente; b) Decisões instrumentalistas guiadas pela eficiência, custo-eficácia, busca por competitividade; c) Ênfase nas relações individuais; d) Autoritária; e) Racionalidade técnica; f) Competição...

Nesse contexto, o papel do diretor da escola passa a ser o de delinear, normalizar e instrumentalizar, enfim, de "gerenciar" a conduta das pessoas para alcançar objetivos e metas desejados. É uma nova forma de vigilância que se instala na escola, instituída pelo sistema de avaliação padronizado, possibilitando a comparação dos resultados entre instituições e redes de ensino. A escola passa a funcionar baseada nas teorias e técnicas da gerência empresarial, o chamado novo gerencialis- 
mo (BALL, 2004; 2006). Isso significa pois, uma transformação organizacional da escola e das atribuições de "ser" professor. Os docentes são transformados em produtores/fornecedores, empresários da educação, sujeitos à avaliação, análise e a comparação de desempenho vinculada ao pagamento que é "um indicador claro das pressões para fazer de nós próprios uma empresa e vivermos uma vida de cálculo" (BALL, 2002, p.6).

A partir desses pressupostos, levanto as seguintes questões: quais são as propostas da política de educação da cidade do Rio de Janeiro que apontam para a perda do seu caráter público, laico e gratuito? Em que medida a atuação/interpretação dos educadores na escola resiste às propostas dessa política?

Nos próximos tópicos, apresento as contribuições de Ball e outros autores, trazendo o conceito de atuação das políticas para analisar exemplos de algumas pesquisas desenvolvidas na cidade do Rio de Janeiro, cujo o tema envolve a política educativa do município.

\section{Conceito de atuação das políticas}

O conceito de policy enactments ou atuação das políticas (BALL, et al., 2016), é um conceito que nos auxilia a pensar sobre como os educadores e as escolas lidam com as demandas trazidas pelas políticas.

A atuação de políticas se opõe as suas implementações, porque elas não são simplesmente adotadas pelos educadores nas escolas. Cada política educativa, que chega às escolas, é interpretada/traduzida de acordo com o contexto de cada instituição. Os educadores estão "envolvidos em processos, lutas, negociações sobre o que certas políticas significam, o que poderia ser feito na prática, como essas interpretações poderiam ser construídas e reconstruídas" (BALL et al., 2016, p.10).

Assim, abre-se um espaço entre os textos legais e as ações cotidianas, nas quais os educadores podem atuar. A atuação deles, segundo Ball et al. (2016) pode ocorrer de duas formas: pela invenção ou pela obediência.

Na primeira ação, os educadores podem usar sua criatividade para engajar-se na política; na segunda, eles podem ser capturados pela ideia da política, submetendo-se a ela.

Essas duas ações dos educadores frente à política, estão alicerçadas em condições objetivas e ao conjunto de dinâmicas "interpretativas" subjetivas por interpretação ou tradução (BALL et al., 2016). 
Diante de uma nova política educativa, os educadores fazem uma interpretação por meio de uma leitura inicial da política, buscando depreender significados para eles das demandas trazidas.

Nessa leitura inicial, eles verificam o que está em jogo e as consequências em aderir ou não à proposta da política. Os educadores/atores avaliam se a adesão ou não à nova política interferirá no orçamento da escola, na classificação em um ranking - IDEB, no caso do Brasil -, além de analisar o tipo de determinação da política no contexto da prática.

Já na tradução, os educadores/atores implementam o processo de transpor a linguagem da política do contexto da produção para o contexto da prática, como ratifica Ball et al. (2016, p.45) “[...] é um processo repetitivo de criar textos institucionais e a colocação desses textos em ação, literalmente, de "atuação".

Tanto a interpretação como a tradução da política são influenciadas pela posição/função e pelo tempo de serviço dos educadores na escola. Se ocupam a função de discentes ou de coordenadores haverá interferência na leitura que farão da política em questão.

Além disso, Ball et al. (2016) destacam a importância das condições objetivas do contexto da prática no processo de interpretação e de tradução da política, a saber:

1. As condições materiais, a localização da escola e sua história

As condições materiais, para os autores - contexto material -, referem-se aos aspectos físicos da escola, incluindo recursos humanos, orçamento e condições de infraestrutura. Os tipos de materiais e equipamentos da escola influenciam nas atividades de ensino e nas possibilidades de interpretação/tradução da política.

2. O contexto situado

Relaciona-se à localização, à história da escola e aos alunos com os quais trabalha. Para Ball et al. (2016), a localização e a história da escola podem atrair ou repelir a escolha dos professores e dos alunos de uma determinada classe social para a escola.

3. A cultura profissional

Refere-se aos valores, a filosofia e aos compromissos dos educadores com as escolas. Esses aspectos interferem no processo de colocação da política em prática, porque os valores e a filosofia de uma política podem não "encaixar" com os princípios defendidos pela escola. Ao passar do texto para a prática, os atores poderão fazer ajustes secundários, 
implementação performática ou se submeterem às determinações da política.

\section{4. $O$ contexto externo}

Relaciona-se a um aspecto mais amplo, local/nacional. Como exemplo, podemos citar a classificação da escola em uma avaliação de larga escala (Prova Brasil, SAEB), o tipo de suporte das autoridades e as relações com as outras escolas.

Por perceber, portanto, que esses fatores interferem no processo de transformar a palavra escrita em ação, analisarei algumas propostas da política de educação da cidade do Rio de Janeiro, mostrando ao leitor que por isso ela está deixando de ser pública, laica e gratuita. Buscarei demonstrar, também, que a atuação/interpretação dos educadores na escola resistem algumas dessas propostas da política.

\section{Rumo à privatização?}

Nesse tópico, abordo algumas formas de privatizações que ocorreram na política educativa da cidade do Rio de Janeiro no período entre 2009 a 20016.

Para Ball (2014) existem várias maneiras de privatizar, como por exemplo, a venda de soluções políticas e melhoria para as escolas por meio de formação continuada, consultoria, treinamento, apoio, melhoria e serviços de gestão. Para o autor, as reformas são oportunidades para as empresas privadas obterem lucros com as propostas da política, pois, geralmente, operam junto com o Estado e as organizações do setor público.

No caso da cidade do Rio, o primeiro exemplo de privatização que trago à discussão, é o projeto "Rio, uma cidade de leitores" que foi regulamentado pela Resolução SME no 1072, de 31 de março de 2010. Teve como objetivo desenvolver o prazer de ler na Rede Municipal de Ensino do Rio, "a partir da mobilização e da articulação de ações entre as escolas da Rede Pública Municipal de Ensino e a sociedade" (SME, 2010, p.1). Percebe-se que no texto da política há brechas para prestadores de serviços para prefeitura, podendo ser voluntários ou privados. Por isso, a Secretaria Municipal de Educação fez uma parceria com o Instituto C\&A e a Fundação Nacional Literatura Infanto-Juvenil (FNILIJ). A escola que fosse vencedora no projeto de leitura contaria com assessores do Instituto C\&A e da FNLIJ para sua formação continuada. 
Nesse exemplo, percebemos que profissionais externos farão parte das atividades na escola. É uma forma de converter bens públicos em privados, porque são profissionais pagos por empresas privadas, prestando serviços e interferindo nas relações, interesses e fins da educação.

De acordo com a Resolução SME n. 1072, "a proposta é estruturada a partir de três eixos norteadores: ampliação e melhoria de acervos; formação de mediadores de leitura e ações culturais de estímulo à leitura". (SME, 2010, p.1).

Dentre as ações para estimular a leitura no município, havia o concurso Escola de Leitores, em parceria com o Instituto C\&A e a FNLIJ. A lógica de estimular o prazer de ler nas crianças através de um concurso imprime uma lógica da competição, aproximando-se da perspectiva da performatividade.

As escolas vencedoras ganharam um prêmio de $\mathrm{R} \$ \mathbf{4 0}$ mil reais, uma viagem para Colômbia para dois representantes da escola e um apoio de dois assessores do Instituto C\&A para acompanhar a formação continuada na escola. Essa reestruturação no setor público por meio de parcerias com setores privados tem proporcionado uma transformação na configuração da gestão escolar, na experiência de aprendizagem, nas práticas de trabalho, nos métodos organizacionais e nas relações sociais.

Uma das escolas vencedoras foi onde realizei a pesquisa de doutorado (LEITE, 2012). A escola se localiza na zona oeste da cidade do Rio de Janeiro, seus alunos possuem condição socioeconômica de baixo poder aquisitivo e, na sua maioria, pais com baixa escolaridade.

Nas observações durante a investigação, percebi que o fato de a escola ter sido premiada com o projeto - "Uma viagem através da literatura" -, proporcionou espaços de formação continuada para os professores na área de leitura e de apropriação do código alfabético. Isso ocorreu porque a escola pôde contar com uma verba do prêmio para convidar dois assessores para acompanhar a formação continuada.

A tradução da política (BALL et al., 2016) pela coordenadora diante da proposta de contar com assessores externos, foi de aproveitá-los a seu favor, planejando com eles uma formação que estivesse de acordo com as necessidades identificadas por ela e as professoras. Assim, a escola passou a ser locus de formação continuada, o que possibilitou a articulação dos temas discutidos na formação com o trabalho desenvolvido pelas professoras no cotidiano escolar. 
Neste caso, houve uma atuação inventiva (BALL et al., 2016) por parte dos educadores dessa escola. A parceria com o Instituto C\&A, por meio de assessores externos da escola, possibilitou que a instituição se mantivesse próxima do que acreditava ser o papel da educação - a formação do ser humano, conforme um dos depoimentos da coordenadora: "a leitura nos faz melhor enquanto seres humanos" (Diário de Campo, 27 de outubro de 2010).

Dois aspectos contribuíram para essa atuação inventiva:

O primeiro era a cultura profissional da escola; lá, havia uma valorização do prazer em ler por todos da equipe. Observei que, apesar do concurso, já existiam atividades com o intuito de despertar o prazer pela leitura, por exemplo, as portas de cada sala exibiam uma poesia de diferentes escritores, como: Nicolas Behor, Luís Fernando Veríssimo, Roseana Murray, dentre outros. Além das poesias nas portas das salas, os murais da escola evidenciavam o valor da leitura fruição, da fantasia e do sonho das crianças daquela comunidade.

O segundo aspecto era o contexto material da sala de leitura, que lhe conferia um lugar de destaque na escola, com um acervo de 4.000 livros. A sala oferecia um ambiente agradável e aconchegante, com um tapete colorido e almofadas para que o leitor sentasse, confortavelmente, para escutar ou ler uma história. Realmente, era um convite à leitura, tamanha exposição de livros nas paredes e nas estantes.

Outro exemplo de privatização na Rede Municipal do Rio de Janeiro, foi o do "Projeto Rio Criança Global (PRCG)" regulamentado pelo Decreto Municipal no 31.187, de 06/10/2009, destinado a ampliar o ensino da língua inglesa.

Esse decreto estabelece algumas ações gerais e específicas, tais como: "qualificação profissional dos professores de inglês, aquisição de material didático, contratação de novos professores, atividades de reforço no contraturno, orientadas pela parceria feita com instituições privadas, dentre outras." (FERNANDES LOPES, 2017, p.30).

É um tipo de privatização na qual uma empresa privada (Learning Factory) oferece ao município formação aos docentes e material para ser usado no Ensino Fundamental I e II. A justificativa dessa parceria foi de proporcionar o desenvolvimento profissional dos docentes para que eles pudessem aumentar seu nível de ensino e aprendizagem.

Será que o município não poderia fazer parcerias de formação continuada com as universidades públicas? Nessas universidades há 
pesquisadores especializados em formação nessa área. No entanto, a parceria foi realizada com uma empresa particular, que desconhece a realidade da cidade e dos alunos.

O material produzido pela Learnig Factory para os anos iniciais do Fundamental I foi a coleção Zip from Zog, voltada às crianças de 6 a 10 anos, com foco na produção oral e ludicidade.

Para o Fundamental II, a coleção chamava-se Interaction, que propunha um trabalho junto dos adolescentes com as quatro habilidades da língua: ouvir, falar, ler e escrever. O fato da Learnig Factory vender materiais para o município é uma forma das empresas participarem nas políticas educativas, tornando-se um negócio lucrativo para muitas empresas. Nas palavras de Ball (2014, p. 157) "é a venda de política como uma mercadoria de varejo".

A pesquisadora Barbosa (2016) observou o trabalho de uma professora de inglês que atuava em uma escola localizada no bairro de Rocha Miranda, que participa do PRCG. A professora é graduada em Letras, português-inglês, por uma universidade pública no Estado do Rio de Janeiro. Já trabalhou em cursos livres de idioma. Atua há sete anos na Rede Estadual do Rio de Janeiro e há quatro anos na Rede Municipal na área de inglês.

Barbosa (2016) aponta que na concepção dessa docente, o programa não é capaz de cumprir com o objetivo de desenvolver processo comunicativo. Nas palavras de Barbosa (2016, p. 65), o programa proporciona "à criança um breve contato com a língua. Ela, a criança, consegue memorizar um grupo de palavras, aprende a pronúncia, reconhece o significado em português, mas não consegue articular um processo comunicativo."

De acordo com a pesquisadora, os fatores que dificultaram o alcance do objetivo do PRCG foi "o grande número de crianças nas salas; o material não atende ao contexto do aluno; indisciplina dos alunos" (BARBOSA, 2016, p. 75).

No caso da pesquisa de Barbosa (2016), o processo de interpretação/tradução da proposta do PRCG foi influenciado pelas condições objetivas, tais como: o tipo de material das aulas de inglês, as condições de infraestrutura das salas (35 alunos) e a falta de apoio da regente da turma e da coordenadora.

O fato de os professores de inglês não ficarem todos os dias com os alunos dificultou o estabelecimento de vínculos e regras. Além disso, 
eles "não têm o apoio dos professores regentes dessas turmas" (BARBOSA, 2016, p.77), tendo que fazer alguns ajustes secundários (BALL et al., 2016) ao programa.

Pelo acima exposto, era evidente que não havia condições materiais e contextuais para desenvolver a comunicação em língua inglesa como esperado pelo PRCG. No entanto, ela conseguiu que os alunos aprendessem o vocabulário e a pronúncia de algumas palavras.

Na pesquisa de Costa (2017), foram entrevistadas sete professoras de escolas participantes do PRCG. A falta de infraestrutura das escolas, as salas lotadas e o número reduzido de aulas de inglês também representaram grandes dificuldades ao trabalho dessas docentes.

Apesar desses fatores intervenientes, nas entrevistas, as professoras relataram algumas estratégias utilizadas para motivar e mobilizar os alunos para as aulas. As professoras tinham mais de dez anos de experiência na docência e, no PRCG, já estavam há cinco anos. Todas eram graduadas em Letras (português-inglês) e a maioria possuía especialização em Língua Inglesa.

Diante dos relatos da pesquisa de Costa (2017), pude perceber que as professoras interpretaram/traduziram a proposta do PRCG de forma inventiva. Vou mostrar alguns exemplos retirados da pesquisa de Costa (2017):

a) Milene levou à sala de aula algumas músicas que os alunos solicitaram. A partir daí ela explica que "a gente vai olhando palavras novas... eles anotam as palavras que querem (aprender) e assim a gente vai fazendo... eu acho que eles estão [aprendendo] o vocabulário... sempre trabalhamos" (COSTA, 2017, p. 184). Outra atividade desenvolvida por Milene foi a simulação do programa de TV "Soletrando", na qual os alunos foram desafiados a aprender uma lista de palavras em inglês. De acordo com a professora, "eu não iria pegar palavra aleatória que eles ainda não tinham visto... não tinham conhecido... e eles estudaram... e assim a gente fez... conseguiu fazer uma final do "Soletrando"... tudo muito simples... mas foi bacana" (COSTA, 2017, p. 185).

b) A professora Sônia relatou que usava o livro sugerido pelo programa e as atividades propostas com algumas adaptações à realidade das crianças. Ela mostrou o exemplo com uma atividade de um dos livros que trabalhava com as bandeiras 
de países, pois em sua perspectiva, considerava muito distante da realidade dos alunos. Então, ela relacionou o tema das bandeiras com os times de futebol brasileiros. "Eu tentei usar uma coisa que eles conhecem... futebol... então... eu parti dos times grandes que eles conhecem... [...] então eu comecei a usar os times de futebol... néh... qual que você conhece?" (COSTA, 2017, p. 192).

c) Giulia trabalha os conteúdos e atividades propostas no livro, mas não deixa de proporcionar o momento da brincadeira. Para ela, "é o momento que eu também me dou o prazer de estar com eles... então quando eu dou massinha" (COSTA, 2017, p.226).

Nesses três exemplos, percebemos que as condições e infraestrutura das escolas são semelhantes: salas de aula lotadas de crianças, localizadas na zona norte e oeste da cidade e crianças da classe de baixo poder aquisitivo. No entanto, em dois exemplos, o da pesquisadora Leite (2012) e Costa (2017), essas condições não foram impedimentos para que fizessem ajustes na política educativa do município.

\section{Ensino religioso na cidade do Rio}

Para discutir sobre a questão da laicidade, selecionei duas pesquisas sobre o ensino religioso, na cidade do Rio de Janeiro, para analisar o processo de interpretação/tradução da política dessa cidade. Não discutirei os prós e contras dessa disciplina no currículo, porque o foco desse artigo é o da atuação das políticas (BALL et al., 2016).

Em 19 de Outubro de 2011, o poder executivo da Cidade do Rio de Janeiro decretou a Lei n. 5.303 que criou o Quadro Permanente de Professor de Ensino Religioso do Município do Rio de Janeiro. No artigo $4^{\circ}$, explicita que o professor deve ser credenciado pela autoridade religiosa competente e aponta as seguintes atribuições desse docente: planejar, executar e avaliar as atividades de ensino religioso, cabendo ao docente "favorecer uma convivência fraterna e harmoniosa nos diferentes espaços sociais, preparando o aluno para a aceitação da diversidade e para o conhecimento da ideia de transcendência a partir de sua tradição religiosa". (RIO DE JANEIRO, 2011).

Deixa explícito no artigo $5^{\circ}$ que a matrícula do aluno no ensino religioso será facultativa, corroborando com a Lei de Diretrizes e Bases 
de 1996 (Lei 9.394), que aponta no seu artigo 33 "o ensino religioso, de matrícula facultativa, é parte integrante da formação básica do cidadão e constitui disciplina dos horários normais da escola pública de ensino fundamental, assegurando o respeito à diversidade religiosa do Brasil [...]".

Mesmo sendo uma disciplina facultativa, deveria ser ofertada para todos os alunos da rede, porém, não foi isso o que observou a pesquisadora Ferreira. Em suas palavras, o ensino religioso no município do Rio de Janeiro era ofertado "apenas para os quartos e quintos anos das escolas de turno único" (FERREIRA, 2017, p.55).

Apresento um exemplo de interpretação/tradução da Lei $n$. 5.303 nas escolas municipais cariocas.

A primeira pesquisa é de Ferreira (2017) que desenvolveu sua investigação em uma escola de Del Castilho, região norte da cidade do Rio, por ser professora da rede desde 2001, e ter presenciados diversos conflitos na escola, muitos deles ligados à questão de religião.

Assim, ao entrar no Mestrado, procurou por meio da pesquisa, analisar a implementação do ensino religioso, confrontando com o que a legislação dispõe a respeito da diversidade cultural no ambiente escolar. Nas palavras da pesquisadora, ela

\footnotetext{
[...] procurou entender o comportamento observado nessa escola, onde nenhum inscrito consta como matriculado no ensino religioso de matrizes afro [...] se tenta buscar algumas razões que elucidem como se negociam nesse espaço de convivência suas concepções identitárias e culturais (FERREIRA, 2017, p.30).
}

Chama-nos atenção no trecho acima, que nem todas as religiões possuem liberdade de se expressar nos espaços públicos. Nesse caso, as crianças de matriz africana não usufruem o seu direito de frequentar e/ ou declararem sua religião, por receio de não serem aceitas ou perseguidas em um espaço que deveria ser de todos.

Selecionei o relato de uma docente entrevistada por Ferreira (2017), que ensina religião evangélica. A professora conta à pesquisadora que fazia o planejamento junto com a colega de ensino religioso católico. De acordo com o relato dessa professora, "preparamos um planejamento unificado, com conteúdos e atividades sobre o respeito às diferenças. Hoje infelizmente, trabalho sozinha". (FERREIRA, 2017, p.55). 
A interpretação/tradução da lei por essas duas professoras de religião de matriz cristã, resultou em um planejamento baseado em atividades sobre o respeito às diferenças, sem explicitar de que forma eram desenvolvidas as propostas. Mesmo assim, denotou que havia uma preocupação, por parte das professoras do ensino religioso, em assumir que a escola está marcada pelas diferenças culturais, étnicas, religiosas, etc.

Ao proporem essas atividades, as duas docentes não silenciaram e nem neutralizaram as diferenças presentes no cotidiano. $O$ fato de discutir com as crianças a esse respeito proporcionou que elas vivenciassem o direito de conviver em uma sociedade plural, inclusiva e democrática.

Nesse exemplo, a atuação da política (BALL et al., 2016) dessas duas professoras, foi de obediência à proposta da lei de ensino religioso.

Os valores e a filosofia das duas educadoras "eram semelhantes" com o texto da política do município, uma vez que havia na lei do município um favoritismo para as religiões de matriz cristã, evidenciado na distribuição das vagas, que de acordo com os dados apresentados por Roif (2016, p. 20), "as vagas ficaram: 55 para credo Católico, 35 para o credo Evangélico e 10 vagas para o credo Afro".

Outro fator, externo à escola, que interferiu nessa interpretação/ tradução, é o fato das educadoras terem uma religião de matriz cristã, que traz como princípio, o respeito humano, que deveria incluir todos os credos e os sem-religiões. Buscavam garantir uma convivência fraterna e harmoniosa, preparando o aluno para lidar com a diversidade.

Esses aspectos, anteriormente citados, estão associados aos conceitos de igualdade e diferença que, de acordo com Candau et al. (2013), o ponto a ser considerado é o lugar e a importância da diferença; é trabalhar, ao mesmo tempo, contra a padronização e contra as desigualdades presentes na sociedade. Muitas vezes, quando pensamos em igualdade, relacionamo-nos à ideia de igualitarismo, que pensado ao extremo, pode nos levar ao totalitarismo proposto por Hitler. Esses todos/ as não são padronizados. Não é essa a proposta que defendemos.

A proposta que abraçamos se baseia na garantia do respeito às diferenças e aos direitos, combatendo as desigualdades sociais. Nosso foco está em negar a padronização e lutar contra as desigualdades na sociedade e no ambiente escolar; está no reconhecimento dos direitos que todos temos, sem que estes produzam nossa uniformização, pois somos seres de direitos, mas também, com diferenças identitárias. 
Portanto, temos o direito de ter ou não uma religião, sem sofrermos nenhum tipo de preconceito em relação a nossa escolha.

A seguir, discutiremos outro exemplo de interpretação/tradução da proposta do ensino religioso.

A escola em que a pesquisadora Roif (2016) coletou seus dados se localiza na Vila Cruzeiro, uma comunidade do bairro da Penha, na zona norte da cidade do Rio de Janeiro.

Roif realizou o concurso para o cargo de professora de ensino religioso Afro e o motivo de sua opção fica claro através de suas próprias palavras: "decidi fazer o concurso de Ensino Religioso optando pelo credo Afro. Foi o meio que encontrei para estar dentro da situação". (ROIF, 206, p.20).

Na pesquisa de Roif (2016), a autora traz um exemplo da busca pela padronização da escola por um único estilo de alimentação.

\begin{abstract}
Um dia a diretora me chamou para conversar sobre a aluna. Dona Aparecida, conhecida como tia Cida contou que Cristiane se recusou a comer feijão preto. Era sexta-feira e, quando se está de resguardo, não se come feijão preto, assim outros alimentos. A menina pediu para trocar o prato, mas a diretora disse que era um abuso e que, na escola dela, todo mundo come igual e, se a menina não quisesse a comida, que jogasse fora. Assim Cristiane fez. Não reclamou e jogou imediatamente todo o prato de comida na lata do lixo do refeitório. Na mesma hora eu retruquei à diretora (ROIF, 2016, p.77).
\end{abstract}

A aluna estava de "resguardo", como era designado por sua religião, que a impedia de ingerir feijão, naquele período, cumprindo uma prática religiosa. A atitude-ação da diretora evidenciou a não aceitação e desrespeito aos preceitos religiosos da aluna.

Assim como Cristiane não "pode" se alimentar de feijão na sexta-feira, outra criança poderá não desejar/não dever ingerir determinado tipo de alimento. A escola pública laica não pode desconsiderar "sentidos" da cultura alimentar da criança, que necessita em certos momentos, alimento diferente das demais.

Por que exigir que todos comam os alimentos oferecidos na merenda?

As crianças não podem exercer a escolha conforme suas marcas identitárias?

Não podem dialogar sobre algo que não concordam? 
No relato acima, a diretora não permitiu à Cristiane o exercício de seu direito, de suas convicções religiosas, de falar sobre o que se passava, configurando uma forma de subalternização. O diálogo, na visão de Freire, "é o momento em que os humanos se encontram para refletir sobre sua realidade tal como a fazem e a re-fazem" (FREIRE; SHOR, 1986, p. 123).

A diretora não oportunizou a relação dialógico-comunicativa, na qual os sujeitos entram em acordo sobre determinado ponto de vista e, sem comunicação, não haverá compreensão entre as pessoas sobre diferentes questões.

Para Freire (2002), a dialogicidade ocorre quando todos os envolvidos se perguntam em torno dos motivos pelos quais estão fazendo de determinada forma alguma ação, qual a finalidade dessa ação, como e o porquê delas. Enfim, o diálogo ocorre pela construção entre envolvidos, de pontos de vistas diferentes, mas nunca pela imposição de uma ideia sobre a outra.

No exemplo supracitado, foi apresentada à criança uma única opção - jogar fora todo alimento presente em seu prato - porque não podia comer feijão às sextas-feiras.

Além da violência do não diálogo, não Ihe foi permitido se alimentar com o restante do cardápio da merenda escolar daquele dia como, algum legume, arroz e/ou proteína; ficou sem nutrição adequada e indispensável ao período escolar diário. Na escola laica, os alunos de todas as confissões religiosas, assim como aqueles que não professam nenhuma religião, devem ser admitidos indistintamente e igualmente respeitados na sua condição de indivíduos em formação.

Nessa escola, houve o rompimento do direito da criança expresso em duas leis. A primeira, é a da Convenção internacional sobre direitos da criança (1989), que aponta no seu artigo 2º o princípio da não discriminação e o direito à proteção contra todas as formas de discriminação, expresso nos seguintes termos:

Artigo 2 - 1. Os Estados-partes respeitarão os direitos previstos nesta Convenção e os assegurarão a toda criança sujeita à sua jurisdição, sem discriminação de qualquer tipo, independentemente de raça, cor, sexo, língua, religião, opinião política ou outra, origem nacional, étnica ou social, posição econômica, impedimentos físicos, nascimento ou qualquer outra condição da criança, de seus pais 
ou de seus representantes legais (CONVENÇÃO INTERNACIONAL SOBRE O DIREITO DA CRIANÇA, 1989, p.2).

Além dessa Convenção, temos o Estatuto da Criança e do Adolescente (ECA) que foi promulgado pela Lei n. 8.069 de 13 julho de 1990, no seu artigo 5०, também aponta a não discriminação das crianças e está expresso que "nenhuma criança ou adolescente será objeto de qualquer forma de negligência, discriminação, exploração, violência, crueldade e opressão, punindo na forma da lei qualquer atentado, por ação ou omissão, aos seus direitos fundamentais." (BRASIL, 1990, s/p).

Nessa escola, a interpretação/tradução da política é performática (BALL et al., 2016), porque os valores e a filosofia da Lei n. 5.303 e da Lei 9394/96 não são condizentes com os princípios defendidos pela direção.

As referidas leis preconizam uma relação, entre profissionais e alunos, baseada na aceitação da diversidade, enquanto a diretora valoriza a padronização na escolha alimentar e, consequentemente, de atitudes únicas e mesma religião/crença para todos.

Ball et al. (2016) aponta que não é fácil pôr em prática uma política; a passagem da palavra escrita para ação é desafiadora para as escolas.

No caso em questão, percebemos que não foi fácil à direção colocar em ação essa lei que propõe conviver com a diversidade. Ao interpretar a Lei n. 5.303, na escola, todos partem dos valores que trazem quando entram na instituição. As crianças e professoras não renunciam às suas religiões, seus valores e crenças ao entrarem em um espaço público, na medida em que tudo isso faz parte da identidade de cada um.

Quando estamos em uma escola, precisamos conviver com a crença e descrença das pessoas que convivemos. Isso não significa "defender o fundamentalismo e/ou proselitismo religioso nas escolas públicas" (ANDRADE, 2016, p.412).

Corroborando com o pensamento de Andrade (2016), Cecchetti et al. aponta que cada um tem o direito de olhar o mundo com suas próprias lentes, não há um único modo de ver. "A defesa de um único ponto de vista representa o fechamento de inúmeras outras possibilidades de olhar a realidade, a partir de outros ângulos, matizes e horizontes - outras formas de concretizar a existência humana" (CECCHETTI et al., 2013, p.207). 


\section{Considerações finais}

Retomando a ideia inicial desse texto, se por um lado a política educativa da cidade do Rio de Janeiro busca imprimir uma lógica baseada no novo gerencialismo e performatividade; por outro lado, cada ator interpreta/traduz a política de acordo com seus conhecimentos prévios, com a proposta de educação e seus valores.

Nos dois exemplos sobre a privatização da educação por meio de parcerias com empresas como a C\&A e o Programa Rio Criança Global (PRCG), pudemos notar que o conceito de atuação das políticas (BALL et al., 2016), contribuiu na identificação dos fatores que levaram os educadores da escola a reescreverem o texto da política no contexto da prática educativa escolar(???)

A primeira pesquisa de Leite (2012) apontou que a interpretação/tradução da política foi favorecida pela aproximação entre valores presentes na política e os defendidos pela coordenadora e professoras, no desempenho do papel de educadoras.

A coordenadora organizou uma formação continuada junto aos assessores das empresas privadas, articulando a proposta externa de projeto de leitura com as necessidades da escola e de suas professoras. Essa formação contribuiu para que a escola continuasse trabalhando com o prazer de ler, com a formação de seres humanos e leitores, além de manter a parceria.

A segunda, a pesquisa de Costa (2017), indicou que as professoras não deixaram de usar o material da Learning Factory, mas fizeram adaptações às atividades, adequando-as aos conhecimentos de seus alunos, por meio de estratégias pedagógicas que conferissem sentido ao processo de aprendizagem, como: soletrando, bandeiras dos times, dentre outros.

Nesses dois exemplos, a atuação inventiva dos educadores, na escola, foi fundamental para promover ajustes na proposta externa e nas atividades dos respectivos livros, ou seja, na política educativa. Eles fizeram valer os valores - formação humana, prazer de ler etc - e seus conhecimentos didáticos - adaptação das atividades ao conhecimento prévio dos alunos -, ajustando a política a favor do que professores/escola defendiam como projeto de escola/educador.

Em relação à proposta do ensino religioso, tanto no exemplo de Ferreira (2017) como no de Roif (2016), o que interferiu na interpretação/ 
tradução da política foram os valores defendidos pelas professoras e a diretora.

Na pesquisa de Ferreira (2017), o trabalho das professoras era baseado na valorização e no respeito à diversidade cultural, independentes do tipo de religião dos alunos. Reafirmo que, mesmo Ferreira (2017) não tendo explicitado o modo pelo qual as professoras trabalharam o tema, o reconhecimento das diferenças foi um passo fundamental para pensar em formas de enfrentamento. Havia uma preocupação da equipe em promover a interação dos alunos, discutir as diferenças, para que eles pudessem relativizar maneiras de se situar diante do mundo e das pessoas. Entretanto, essa discussão teria sido mais proveitosa e ampliada, se todos os alunos pudessem matricular-se em qualquer disciplina de ensino religioso, sem sofrer bullying ou preconceitos por escolher uma religião de matriz afro.

A pesquisa de Roif (2016) também mostrou uma interpretação/ tradução da política baseada no valor da direção da escola pela padronização.

A escola é um lugar de trânsito de culturas, por isso, "não compete buscar homogeneizar, mas garantir a liberdade religiosa, por meio da igualdade de acesso ao conhecimento de todas as culturas, tradições/ grupos religiosos e não religiosos, promovendo os direitos humanos e a justiça cultural" (FLEURI et al., 2013, p.15).

Mesmo que esse exemplo tenha apontado esse achado, Roif (2016) por meio de sua pesquisa expôs processos de exclusão e desigualdades sofridos pelas crianças que professam uma crença diferente da direção da escola.

Considero que cada instituição deveria trabalhar com seus alunos para romper com relações de poder que encobrem e naturalizam estereótipos, discriminações e preconceitos.

Nesse ensaio, os exemplos mostraram uma predominância significativa dos valores defendidos pelos educadores na interpretação/tradução da política. No conceito proposto por Ball et al. (2016), não houve nenhum destaque/hierarquia em relação aos fatores envolvidos no processo de interpretar/traduzir a política do contexto do texto à prática. Penso que mereça ser mais investigado esse fator na atuação das políticas, porque Ball (2014) menciona que a performatividade tenta mudar as subjetividades dos educadores. Isso não foi observado nesse ensaio e, mesmo tendo apresentado somente três exemplos, entendo que seja um indício a ser 
mais estudado. Esses docentes não foram capturados pela lógica da política; não passaram a agir calculando suas ações, pensando nos impactos e nos resultados de desempenho mensuráveis de sua turma. Na verdade, não mercantilizaram seu trabalho educativo; pelo contrário, eles baseavam suas decisões visando e priorizando à aprendizagem de seus alunos. Por isso, cumpriam a proposta da política do município adequando-a a seus propósitos e valores que defendiam enquanto educadores.

Portanto, enquanto tivermos atores, na escola, comprometidos com a formação humana e aprendizagem dos alunos, a escola pública, laica e gratuita continuará a ser defendida e frequentada por nossas crianças e jovens.

Para que esses educadores continuem existindo e trabalhando nas escolas públicas, laicas e gratuitas, é imprescindível valorizar a profissão docente por meio de cursos de formação continuada nas escolas, de acordo com as necessidades dos docentes e dos projetos políticos pedagógicos dessas instituições, e investir em salários dignos para todos e não ligado a bônus e/ou competições entre educadores e escolas.

\section{Referências}

ANDRADE, Marcelo. A intolerância religiosa como experiência escolar: um desafio para a educação intercultural. In: CANDAU, Vera Maria (org). Interculturalizar, descolonizar, democratizar: uma educação outra? 1 ed. Rio de Janeiro: 7 Letras,2016. cap 2, p.394-418.

BALL, Stephen J. Reformar escolas/reformar professores e os terrores da performatividade. Revista Portuguesa de Educação, Braga, Portugal. v.15, n.2, p.3-23, 2002.

- Performatividade, privatização e pós-estado do bem-estar. Educação e Sociedade, Campinas, SP, v.25, n. 89, p. 1105-1126, set./dez. 2004.

Sociologia das políticas educacionais e pesquisa crítico-social: uma revisão pessoal das políticas educacionais e da pesquisa em política educacional. Currículo sem fronteiras, Porto Alegre, v. 6, n.2, p.10-32, jul./dez. 2006.

Educação Global S.A: novas redes políticas e o imaginário neoliberal. Tradução de Janete Bridon. Ponta Grossa: UEPG, 2014. 
BALL, Stephen J; MAGUIRE, Meg; BRAUN, Annette. Como as escolas fazem as políticas: atuação em escolas secundárias. Tradução Janete Bridon. Ponta Grossa: Editora UEPG, 2016.

BARBOSA, Suellen do Nascimento. Crenças de uma professora de inglês no contexto do programa rio criança global. Dissertação (Mestrado em Estudos de Linguagem) - Universidade Federal Fluminense. Instituto de Letras. Programa de Pós-graduação em Estudos da Linguagem. 2016.

BRASIL. Estatuto da Criança e do Adolescente. Lei № 8.069, de 13 de julho de 1990.

BRASIL. Lei Diretrizes e Bases n.9.394, de 20 de Dezembro de 1996. Disponível em: <http://www2.camara.leg.br/legin/fed/lei/1996/lei9394-20-dezembro-1996-362578-normaatualizada-pl.html>. Acesso em: 11 abr. 2011.

CANDAU, Vera Maria; PAULO, Iliana; ANDRADADE, Marcelo; LUCINDA, Maria da Consolação; SACAVINO, Susana; AMORIM, Viviane. Educação em Direitos Humanos e formação de professores (as). São Paulo: Cortez, 2013.

CECCHETTI, Elcio; OLIVEIRA, Lilian Blanck de; Hardt, Lúcia Schneider. Educação, diversidade religiosa e cultura de paz: cuidar, respeitar e conviver. In: FLEURI,Reinaldo Matias; OLIVEIRA, Lilian Blanck; HARDT, Lucia Schneider; CECCHETTI, Elcio; KOCH, Simone Riske. Diversidade religiosa e direitos humanos: conhecer, respeitar e conviver. Blumenau: Edifurb, 2013. cap 1, p.203-228.

CONVENÇÃO INTERNACIONAL SOBRE OS DIREITOS DA CRIANÇA.1989. Disponível em: <https://www.unric.org/html/portuguese/humanrights/ Crianca.pdf >. Acesso em: 08 jun. 2017.

COSTA, Dilermando Moraes. Atividade de trabalho e invenções de si: um estudo de narrativas autobiográficas de professoras de inglês do Programa Rio Criança Global. 2017. Tese (Doutorado em Humanidades, Culturas e Artes) - Universidade do Grande Rio Professor José de Souza Herdy. Duque de Caxias, 2017.

FERNANDES LOPES, Cristina. Conflitos discursivos em torno do Programa Rio Criança Global e o ensino de espanhol como língua estrangeira no Município do Rio de Janeiro. 2017. Dissertação 
(Mestrado em Letras Neolatinas) - Universidade Federal do Rio de Janeiro, Rio de Janeiro, 2017.

FERREIRA, Paula Helena Nacif Pereira Pimentel. História oral e conflitos no ensino religioso: narrativas de professores e estudantes de uma escola pública da periferia do município do Rio de Janeiro. 2017. Dissertação (Mestrado em Humanidades, Culturas e Artes). Universidade do Grande Rio "Professor José de Souza Herdy", Duque de Caxias, 2017.

FLEURI, Reinaldo Matias; OLIVEIRA, Lilian Blanck; HARDT, Lucia Schneider; CECCHETTI, Elcio; KOCH, Simone Riske. Diversidade religiosa e direitos humanos: conhecer, respeitar e conviver. Blumenau: Edifurb, 2013. $232 \mathrm{p}$ FREIRE, Paulo; SHÖR, Ira. Medo e ousadia: o cotidiano do professor. Rio de Janeiro: Paz e Terra, 1986.

Extensão ou comunicação? 12. ed. Rio de Janeiro: Paz e Terra, 2002.

GEWIRTZ, Sharon; BALL, Stephen J. Do modelo de gestão do Bem-Estar Social ao novo gerencialismo: mudanças discursivas sobre gestão escolar no mercado educacional. In: BALL, Stephen J.; MAINARDES, Jefferson. Políticas Educacionais: questões e dilemas. São Paulo: Cortez, 2011. cap. 8, 193-221.

LEITE, Vania Finholdt Angelo. A atuação da coordenação pedagógica em conjunto com os professores no processo de recontextualização da política oficial no $1^{\circ}$ ano do Ensino Fundamental no Município do Rio de Janeiro. 2012. Tese (Doutorado em Educação) - Pontifícia Universidade Católica do Rio de Janeiro, Rio de Janeiro, 2012.

MARTINS, Joana. SME distribui os livros que irão compor a Biblioteca do Professor. Prefeitura da Cidade do Rio de Janeiro. 13 abr. 2010. Disponível em: <http://www.rio.rj.gov.br/web/sme/ exibeconteudo?id=674709>. Acesso em: 10 abr. 2018.

RESOLUÇÃO SME No 1072, DE 31 DE MARÇO DE 2010. Publicada no Diário Oficial de 05 de abril de 2010. Disponível em: portais.rioeduca.rio. gov.br/.../RESOLUÇÃO\%20DE\%20SALA\%20DE\%20LEITURA. Acesso em: 10 jan 2012.

RIO DE JANEIRO (cidade). Decreto n. ${ }^{\circ} \mathbf{3 1 . 1 8 7}$, de 06 de outubro de 2009. Cria o Programa Rio Criança Global no âmbito da Secretaria Municipal de 
Educação. Diário Oficial do Município do Rio de Janeiro, Poder Executivo, ano XXIII, n॰138, 07 de out. de 2009, p. 5.

Secretaria Municipal de Educação. Resolução SME n 1072,

de 31 de março de 2010. Dispõe sobre a estrutura e o funcionamento das Salas de Leitura nas Unidades Escolares da Rede Pública do Sistema Municipal de Ensino do Rio de Janeiro e dá outras providências. Disponível em: portais.rioeduca.rio.gov.br/.../RESOLUÇÃO\%20DE\%20 SALA\%20DE\%20LEITURA Acesso em: 20 jun 2011.

. Lei Ordinária № 5.303 de 19 de Outubro 2011. Cria no Quadro Permanente do Poder Executivo do Município do Rio de Janeiro a categoria funcional de Professor de Ensino Religioso e dá outras providências. Disponível em: <http://mail.camara.rj.gov.br/ APL/Legislativos/contlei.nsf/b24a2da5a077847c032564f4005d4bf2/ e23e957096b94f918325792f0068141e?OpenDocument\&Collapse View>. Acesso em: 01 jun 2018.

ROIF, Patrícia de Oliveira. Narrativas de uma professora de Ensino Religioso Afro em escolas do município do Rio de Janeiro. 2016. Dissertação (Mestrado em. Universidade do Estado do Rio de Janeiro, Rio de Janeiro, 2016.

Recebido em: setembro /2018 Aprovado em: novembro/2018 